\title{
KNOWLEDGE MANAGEMENT VIA ERASMUS PROGRAMMES
}

\author{
Irina Ioana BOCIANU*, Sorin Adrian CIUPITU** \\ * University of Bucharest, Bucharest, Romania \\ ** Politehnica University of Bucharest, Bucharest, Romania \\ irina.bocianu@lls.unibuc.ro; ciupitu.sorin@yahoo.com
}

\begin{abstract}
Living in a highly competitive society which is becoming more and more globalised and students evolving into "digital natives", students deriving from the European Union countries have benefitted from the Erasmus programmes in an attempt to become aware of the common European culture, education and labour market. Under these circumstances, the present paper addresses the issue of knowledge acquisition via Erasmus programmes and how knowledge management is operated as a result of these study opportunities. For our endeavour, we have conducted an online quantitative and qualitative study with the students from the University of Bucharest and Politehnica University of Bucharest who have benefitted by the programme. As expected, the students' answers came to confirm our hypotheses that the exchange programmes are useful in this sense at the same time that information and experience that benefits students should be exploited and managed more in the Romanian academic life for the labour market.
\end{abstract}

Keywords: Erasmus programme, knowledge acquisition, knowledge management, student, culture

\section{Introduction}

The university programme called Erasmus, created in 1987, was conceived with the clear purpose of allow student mobility in the EU. This experience exchange both for the Romanian and foreign students, is beneficial from several points of view. Still, the drawback represented by the programme is the fact that the Romanian students are tempted to leave Romania at the end of the programme in order to work abroad due to higher remuneration. One possible measure to be taken would be that the government takes urgent action to stop brain exodus because fields such as science, innovation, scientific research and technology transfer are a national priority as stipulated in the Romanian constitution and main laws which regulate these fields. The importance of scientific research, technology development and technology transfer was based on the essential role played by science and technology for societal development representing the main source of progress in all human activity fields. For this reason, science and technology are on similar level with the education systems within the European Union facilitated by the Erasmus programmes.

\section{Erasmus programmes as knowledge providers}

The Bologna Process (1999) together with the Lisbon Recognition Convention (1997) have come to fulfil the need for a European common framework for qualifications, grading system, quality management and quality assurance. At the same time, the objectives of a system oriented towards scholarships, as the Erasmus programme is, 
are to facilitate the collaboration and cultural interchange between European countries in an attempt to obtain a equal European market with workforce adapted to its requirements. As a programme with a specific purpose of educating students deriving from the higher education environment, it is important how the knowledge acquisition is managed by the home institution as a result of the programme. At the same time, the cultural and social aspects are to be taken into account when analysing the outcomes of the exchange programme for students to become knowledge producers in highly digitalized environments.

The programme is a facilitator of cultural interaction between the host and the visiting country. Gestures which for some cultures mean politeness, may seem offensive for other cultures which highlights the idea of diversity. But by being aware of the others' culture (in terms of religion, symbolism, unwritten rules, ethnic aspects) the degree of tolerance grows towards them and their acts and this significantly reduces the number of conflicts within highly diverse community such as the European Union.

In this sense, Seza Zerman believes that "exposure to different cultures and different styles of education is one purpose of the Erasmus program, and it can be concluded that the change in students' expectations is inevitable at the end of the program" [1]. At the same time, Manuel Otero believes that an important aspect of the outcomes of the programme in that "the number of Erasmus students has been increasing strongly since the set up of the programme, whereas returns to participation in the programme in labour market terms seem to be diminishing" [2] taking into account the fact that the financial differences between the students deriving from different countries with different life standards is an important issue regarding the programme. According to him "in the richer counties students from families in the highest national income levels participate in the programme more frequently. By contrast, it is in the poorer countries that we see less people from higher socio-economic backgrounds participating in the programme. This may highlight two different motivations for mobility: the predominance of mobility for 'consumption' from higher socio-economic groups in higher income countries versus mobility for 'investment' from less well off people from lower income countries, the other countries falling somewhere in between these two extremes. [2]

Nevertheless, the main role of the Erasmus programme "is essential for employability and competitiveness, social inclusion, active citizenship and personal development. The challenge is to provide learning opportunities for all adults, throughout their whole life, especially disadvantaged groups who need them most" [3] issued by the European Commission stressing the idea that the role taken by the programme is to make education abroad affordable to extended number of students coming from different fields of education and economic backgrounds thus facilitating the contact with learning environments, cultures, civilizations and approaches to somewhat similar subjects as those of their curricula for extending knowledge horizons.

In terms of cultural adjustment to the new learning and teaching environment, Alina Brasoveanu draws attention to the adjustment stages that students undergo when arriving at the host institution stating that "the social groups that Erasmus students form in the first period of the semester they spend abroad are mostly intercultural, or even constituted only by students that share the same status - the Erasmus student or "foreigner" one. Thus, the usage of the term 'community' becomes relevant in order to address this interactive phenomenon" [4] observing the relevance of the feeling of belonging to a community while studying abroad. In the same line of thought, Karina Oborune explains that the 
cultural European identity is the European Union's design facilitated by the Erasmus and other mobility programmes as a "socially constructed feeling of belonging to the European community based on shared interests and experiences" [5] which is an important aspect to take into account when globally thinking of a European identity. In the same line of thought, Laurence Romani explains the fact that, although specialised literature on culture management has tried to create "cultural dimension frameworks that enable comparisons between countries" [6] these sets of rules do not actually succeed to predict how people interact: "[these frameworks] cannot adequately predict or explicate what happens when people actually meet" [6].

At the same time, Yulcesin-Tas highlights some of the most important issues experienced by the Erasmus students: "the most important problem encountered before going abroad is the late arrival of documents from the universities abroad, the most important problem encountered during their education abroad is the lack of sufficient foreign language competence, and the most prominent problem encountered after their return is the matching of courses" [7]. Thus, issues regarding red tape, previous language acquisition and similar curricula are major aspects regarding the drawbacks of the scholarship. Nevertheless, the lack of curricula resemblance observed by Yulcesin-Tas seems to be quite important as the ECTS (European Credit Transfer and Accumulation System) has been especially designed so that students studying abroad do not meet discrepancies regarding subjects studied in a certain area as these are designed in accordance with the qualifications framework established by the Lisbon Recognition Convention in view of a common labour market.

For this reason, the present paper further analyses a series of answers obtained from Erasmus students who have either come to
Romania or left Romania to study abroad via the programme with a view on how the entire process is being managed and/if it should be improved.

\section{Data sampling and objectives}

We have designed an online survey questionnaire regarding the Erasmus programme to which we have received a number of 106 answers out of 200 emails sent both to students leaving Romania and visiting Romania within the programme.

The research combines comparative and statistic analysis our interest being driven from the programme efficiency. Thus, via transmission and learning, culture is "closed in a self-producing and self-reproducing system" becoming "not only a highly complex product, but also a producer of high complexity" [8]. As a result, culture represents the generating/regenerating memory of social systems in general and economic in particular.

A training opportunity in a foreign country represents more than personal development of the student undertaking the mobility programme. In a changing European environment, after the Brexit and the UE-27 Summit and Treaties of Rome at 60 (2017), we notice a change in the European Union management. The five scenarios envisaged by the EU Commission's White Paper on the Future Of Europe are as follows: "Carrying On; Nothing but the Single Market; Those Who Want More, Do More; Doing Less, more Efficiently; Doing Much More Together" [9]. Under these circumstances, the EU economic future is quite uncertain, with no clear official direction expressed, which makes EU less developed countries, such as Romania, struggle more to become a stronger economic power. Thus, the utility of the Erasmus programme is vital as it makes direct contact for the Romanian students with the new EU realities of the sole EU market. 


\section{Results and Discussions}

The students taking part in the questionnaire survey are enrolled in undergraduate and postgraduate programmes. Some of the respondents considered the study period as too short while others considered it as sufficient.

Part of the respondents have answered that they have chosen Romania because they were interested in the Romanian culture, student life and, the desire to feel independent, make new friends develop professionally and personally.

The materials provided by the host institution were, in their opinion, quite enough. More information about the study programme was provided by friends or facilitated via the internet being useful in a proportion of $52 \%$.

When arriving in Romania, they have been welcomed with a festive dinner and were offered information and being aided by a guide. They have declared themselves $100 \%$ satisfied with the welcoming events. Regarding the information provided by the Erasmus Office, opinions differed by $75 \%$.

The majority of students were accommodated in the student hostels provided by the host university.

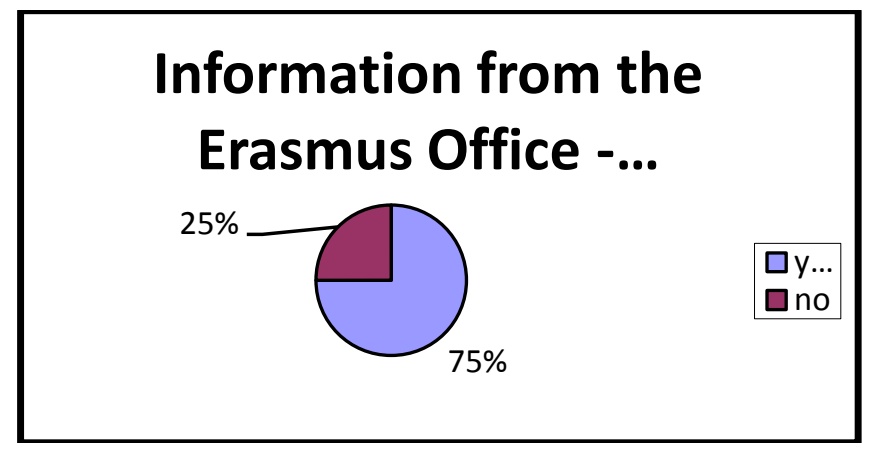

Figure 1 Erasmus Student Information Satisfaction

The students have benefitted by foreign languages classes so that their evaluation underdone via the present survey revealed a sense of growing language acquisition from $33.3 \%$ before the programme to $66.7 \%$ at the end of the programme. All students have signed a study contract, took part in exams, were given ECTS and their studies will be acknowledged abroad.
The students' expenses have been $50 \%$ covered by the scholarship and $50 \%$ by their families having in view the fact that they have not payed any tuition fees.

One of the objectives represented by the mobility is personal development and it has been reached as we can see from the following figure:

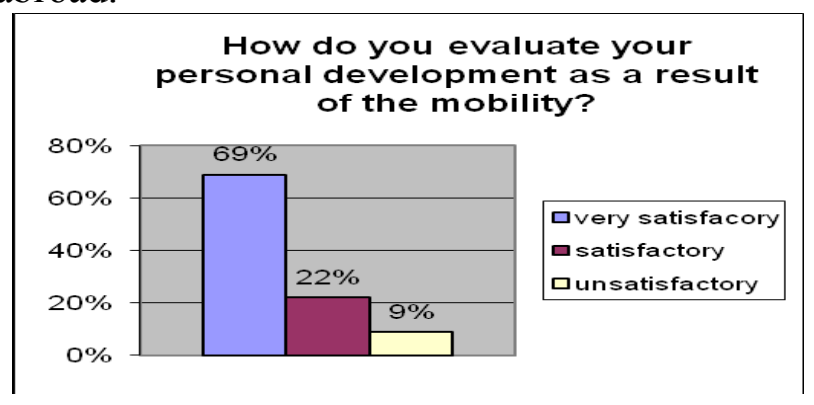

Figure 2 Self-evaluation in terms of personal development 


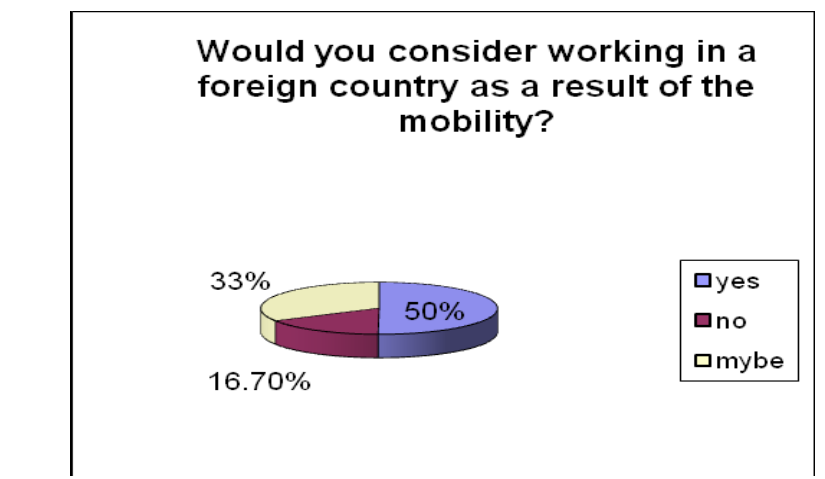

Figure 3 Working in a foreign country after the mobility

The experience lived facilitated by the Erasmus programme will help the students in their future careers.
The programme was well evaluated as we can see from our survey that there is room for improvement.

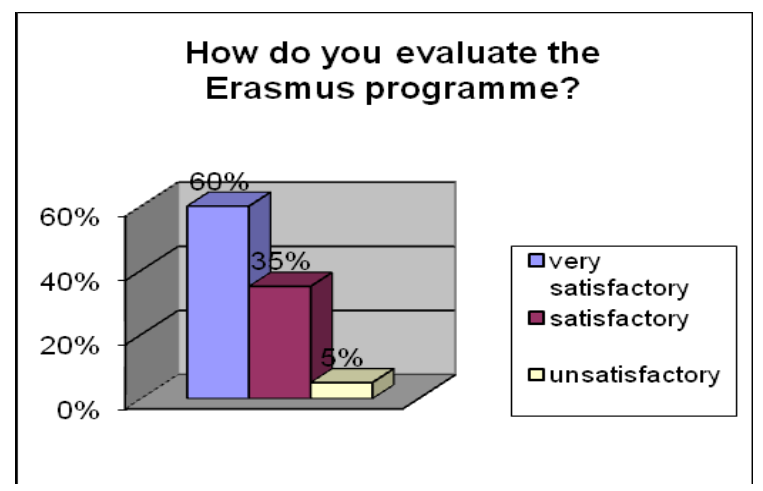

Figure 4 Evaluation of the Erasmus programme by students

\section{Conclusions}

As we can notice, the Erasmus programme is quite useful and benefits students for their personal and professional development. At the same time, we can notice that some of the major issues remarked by Yulcesin-Tas are being preserved in Romania and other countries as well. Issues such as bureaucracy, financial differences, language acquisition can be found in all European Union countries participating in the exchange programme. Nevertheless, in order to have improved mobility programmes, a series of actions should be undertaken so that the management of knowledge runs without administrative obstacles.

The following suggestions made by the students participating in the survey would make a contribution for the programme improvement. Thus, course descriptions, longer welcoming period, money allowance payed every month so that they do not struggle for extra funding, activities to get accustomed to the host country culture and civilization, better cohesion between universities and higher scholarship as some countries are more expensive than others are just a few of the points to be reconsidered when talking about the Erasmus programme. We can also notice the importance offered by the programme as the students are becoming more independent thinkers and content producers. These types of activities which stimulate and oblige students to take action and manage in a different environment in all walks of life, prepare them to become responsible, forward adults, who will not reject unpredicted situations but will be 
glad to the challenges and provide original solutions especially in a digitalized world. It also helps them develop critical thinking, creativity, analyze and evaluate information moving forward from the well-established objective of LLL (Long Life Learning) towards what Norman Jackson calls Life Wide Learning (LWL) [10] in their personal development.

When referring to the roles fulfilled by higher education institutions, Peter Drucker's words "no business today [...] has a fraction of the power the big university has. By granting or denying admission or the college degree, the university grants or denies access to jobs and livelihoods. Such power no business or other institution ever had in American history" [11] stretching his thinking to Europe which in his opinion follows the same pattern: "in Europe things are only slightly different" [11].

For this reason, Romania should take more care of the younger generation and design a knowledge management system oriented towards them in order to preserve the valuable young people unless brain exodus intensifies.

\section{References}

[1] Zerman, Seza, The Impacts of Studying Abroad. Opportunities on International Students, online, New York, Rochester Institute of Technology Printing House, 2014, p.4.

[2] Otero Manuel, International Review of Education, no 54, vol. 2, pp. 135-153, 2008.

[3] http://ec.europa.eu.

[4] Brasoveanu Alina, Studia Europea, vol. LV, no. 4, pp. 85-104, 2010.

[5] Osborne Karina, Quo Vadis, Europo?, no. 5, vol. 35, pp. 75-94, 2015

[6] Romani Laurence, Primecz Henriett, Sackmann Sonja, Cross-Cultural Management in Practice: Culture and Negotiated Meaning, online, Edward Elgar publishing House, p. 2, 2011

[7] Yulcesin-Tas, Yaprak, Journal of Instructional Psychology, vol. 40, no 3, p. 81-87, 2013.

[8] Morin Edgar, Lost Paradigm: Human Nature, print, Iasi, Alexandru Ioan Cuza Printing House, pp. 80-81, 1999.

[9] http://ec.europa.eu

[10] Jackson, Norman, Learning for a Complex World: A Life Wide Concept of Learning, Education and Personal Development, online, Washington, AuthorHouse Publishing, 2011, p. 351.

[11] Drucker, Peter, Management. Tasks, Responsibilities, Practices, online, New York, Truman Talley Books Publishing House, p.10, 1986. 